\title{
Feminist Pedagogy and Education in Values
}

\section{Mark T. Brown}

\section{University of Wisconsin Center-Marathon County}

The teaching of value-laden courses in the social sciences and the humanities, particularly philosophy and history, poses special demands upon balance in course content and instructional technique. The western tradition in ethical thought converges upon a specific approach to moral problems, an approach that too often fails to connect with the concerns of women, ethnic minorities, and other groups outside the cultural mainstream. Moral problems are traditionally understood in terms of competing ethical theories involving abstract moral principles. This type of subject matter naturally lends itself to a deductive, lecture-oriented instructional format. The structure of one or more ethical theories is sketched, the key concepts defined, the basic principles analyzed, and the moral problem itself resolved as an application of the ethical theory in question. Many undergraduates implicitly reject this approach to value conflict by rejecting the conclusions of apparently cogent arguments derived from classical ethical theory. This phenomenon has prompted reflective educators to reconsider their accustomed analytical tools and the classroom atmosphere that use of those tools engenders.

In this essay, I will consider briefly an alternative approach to teaching value-laden courses found in the feminist pedagogy inspired by the work of Carol Gilligan and developed by Nell Noddings, among others (Gilligan, 1982; Noddings, 1984). To supplement the traditional hierarchy of moral principles, Gilligan and Noddings urge greater emphasis upon the web of interpersonal relations and responsibilities embedded within the social context in which moral dilemmas and value conflict arise. They argue that the range of choice open to a moral agent depends crucially upon the special personal relationships and emotional attachments of the particular individuals involved. I will suggest that careful attention to these 
insights can result in more effective instruction in the critical assessment of value conflicts and can point toward a model of undergraduate education that better prepares students to cope with difficult choices in their own lives. Feminist pedagogy thus directs our attention toward both alternative methods in the teaching of values and the values implicit in the education students receive.

\section{Two Models of Moral Development}

Instruction regarding the moral, personal, and social policy implications of abortion illustrates the need for a fresh approach to learning about values. Arguments that take as premises the role in ethical theory of such personal characteristics as consciousness, rationality, and the experience of pleasure and pain, and draw conclusions concerning the moral status of the fetus often appear remote and aridly abstract to undergraduates. Similarly, considerations of historical precedent, cost-benefit calculations, and the dictates of theological doctrine can leave undergraduates unmoved, unconvinced, and uninterested.

Some educators are tempted to treat this kind of unresponsiveness as evidence of incomprehension and moral immaturity. After all, it is thought that the issue of abortion clearly falls under these ethical principles or within the scope of that legal precedent, or has such and such positive and negative social consequences. The fault thus lies with the student for failing to grasp the deductive subsumption of a value-laden issue, in this case abortion, within a more inclusive intellectual framework.

This type of attitude from teachers often springs from a theory of moral development associated with (but not endorsed by) the Harvard psychologist Lawrence Kohlberg (Kohlberg, 1981). Moral development is seen as a progressive detachment of personal and subjective attitudes in favor of more neutral and objective categories of evaluation. Early concentration upon personal rewards and punishment gives way to concern with social acceptance and respect for the conventional rules of the family, group, and nation. At the pinnacle of moral development, moral agents deduce rules of conduct from the fundamental principles of ethical theory.

Carol Gilligan and others have subjected this model of moral development to vigorous criticism. Gilligan found that the thinking of many women who considered having an abortion would be classified as merely conventional, and that these same women, when interviewed some years later, actually had regressed on this scale of moral development. Gilligan suggested that women and perhaps cultural minorities respond 
to issues of value conflict in a fashion that is different from, but not necessarily incompatible with, this model. She argued that the history of the personal relationships and the biographies of the people involved in a value conflict can be crucial to an incisive analysis of the moral problem that results, and that the women she interviewed implicitly recognized this. In many situations, concentrating upon the details of social context can be exactly the right approach, while premature attention to abstract moral principles can be an unhelpful distraction. This alternative way of thinking about moral problems is at once more accessible to large segments of the population and more productive of genuine understanding of the concrete reality of the clash of interests and claims of right. On this model of moral development, student unresponsiveness to traditional ways of treating value conflict reflects both the one-sided character of traditional ethical analysis and student dissatisfaction with the teaching methods that are its natural companion.

Conventional, teacher-centered instructional methods are seen as guided by the judicial paradigm of blind justice. An ideal judge dispassionately dispenses rewards and punishments while maintaining strict neutrality towards the persons involved. Traditionally in education, the perspective of an uninvolved third party is seen as the proper vantage point from which to describe social conflict. The web of interpersonal connection is intentionally deleted from the judicial model of conflict resolution; at the same time, instruction by deductive subsumption distracts attention from the details of social context that can bring to life the diversity of social interaction.

Perhaps an attitude of studied impartiality is appropriate from a governing official, but for those to whom they matter most, moral dilemmas are lived from within a specific interpersonal context. From the perspective of the participants in a crisis situation, the bonds of family, friendship, personal responsibility, and loyalty are absolutely crucial and cannot be factored out of the equation without at the same time draining the resulting analysis of cogency. For Gilligan, sensitivity to the role of personal relationships should be seen as a means to achieve a realistic assessment of the available options. In the classroom, concentrating upon abstract legal, ethical, or religious principles can obscure the details of interpersonal connection that many students intuitively believe to be essential to a deep understanding of actual cases of value conflict.

Gilligan contends that this more immediate and contextual approach to moral agency is to be found more frequently among girls and women than among boys and men. She cites empirical studies that support this 
claim and traces this divergence in thought patterns to the dynamics of psychosexual development. She argues persuasively that girls tend to identify the developing self with their mothers and to see this connection to an Other as essential to their social identity. In contrast, sex role socialization for boys typically leads to a felt need to sever the psychological tie between self-image and mother-image. Boys and men often come to see independence and self-reliance as signs of emotional maturity. Partly as a result, classical liberal justifications of an inviolable sphere of privacy and Kantian claims of the moral primacy of personal autonomy strike many men as virtually self-evident maxims of conduct. Interference in the affairs of another person is seen as wrong; non-interference is seen as recognition of the equal rights of others.

Gilligan claims that the experience and psychology of many women resonates more deeply with an interpretation of moral agency that takes seriously the contextual background of social interaction. In this alternative interpretation of value conflict, selfishness and self-absorption are seen as wrong; helping others and maintaining the bonds of personal connection are seen as right. Individuals are seen not as neutral bearers of rights and centers of independent agency, but rather as persons defined in large measure by their status within a network of special relationships and emotional attachments. Many women think that the proper approach to cases of value conflict resides not in the rational adjudication of competing interests, but rather in drawing upon and maintaining existing lines of interpersonal connection in order to restore and strengthen the bonds of community and to satisfy all parties to the extent possible.

Gilligan does not claim that men invariably find the deductive approach most natural or that women in general adopt a more contextualist attitude. Clearly, many men and many women exemplify both patterns of thought, but the nearly exclusive emphasis in undergraduate education upon deductive hierarchy often distorts the social reality of value conflict and distorts it in a way more likely to be felt by women students than by men students.

\section{Implications for the Teaching of Values}

What can (and what should) be done to address this kind of imbalance in undergraduate education? In philosophy courses, contextualist interpretations of value judgements can be taught alongside the survey of ethical theories, while the analysis of appropriate emotional response can be conducted in conjunction with the analysis of moral argument. The feminist critique of traditional models of moral development can be 
integrated into the review of ethical theory, and alternative frameworks for the analysis of value conflict can be presented explicitly in the classroom; but one must not fall into the trap of embedding these ideas in yet another lecture. Feminist pedagogy should inform both course content and classroom management.

Social science and history courses, as well as courses specifically designed to confront moral problems, could benefit from supplementing primary source and textbook readings with case studies of value conflict. Case studies bring home to students the immediacy of moral problems and provide a useful format to display both abstract principles and the relevance of social context. The use of case studies can be combined effectively with cooperative learning techniques. Often students in groups of four or five feel free to express their thoughts openly, especially when the abstract concepts are pegged to a narrative describing named individuals involved in actual situations.

\section{Implications for Values in Teaching}

Recognition that the classroom itself is an arena of social interaction and personal relationships is equally important. Highly structured, teacher-oriented classroom management implicitly endorses a formal and hierarchical model of social interaction. An instructor who models the traditional deductive approach through well-organized lectures and readings also can model the contextualist approach by promoting a classroom atmosphere in which nontraditional responses to questions of value choice are welcomed.

Recent research has indicated that women students are more likely to be discouraged from active participation in their own education. College professors, whether male or female, call upon the raised hands of male students more often than the raised hands of female students, interrupt their female students more frequently than their male students, and, in general, are more likely to reward their male students with verbal praise. Partly as a result, female students tend to be much more tentative in the classroom. Women students typically frame their contributions in the form of questions rather than assertions; and when declarative statements are made, they often will be prefaced by qualifications of subjectivity ("I feel that ...") or followed by interrogative trailers (“... don't you think?"). Testimony from college teachers indicates that their behavior is unintended and unconscious. Greater sensitivity to what Bernice Sandler calls the "chilly classroom climate" for women can lead to just the sort of 
social diversity and learning by doing that feminist pedagogy has long recommended.

Explicit avowals in the classroom of the insights of contextualist accounts of value judgement should be reinforced by the teacher's implicit recognition of the importance of personal relationships in the process of education. Students should know that their understanding of the subject is more significant to the instructor than the quantity of material covered, the pace of instruction, or a pre-set sequence of assignments. To the extent that the subject matter permits, syllabi should be flexible in the sense that time is budgeted for "falling behind," expanding or contracting various aspects of the course, and rearranging the sequence of topics studied.

More than anything else, grading discloses the distinctive and inherently unequal character of the teacher/student relationship. This asymmetry should be neither avoided nor denied. The importance of the details of personal relationships in eduation as elsewhere is one of the key insights of the view Gilligan and Noddings urge.

Teachers must view their subject matter through the eyes of their students if students are to grasp and retain the material (Noddings, 1984). The teacher's interpretation of course content needs to be presented in language the student can grasp and in a form that encompasses the student's motivation and (possibly ill-understood) goals. This ability to include within their own subjectivity the subjectivity of the student is the mark of effective teachers.

Grading threatens effective teacher/student relationships in part because it encourages the student to attempt a similar inclusion of the teacher's subjectivity. Education can become an elaborate guessing game for students in which academic success results in large measure from skill in anticipating the teacher's instructional goals and preferred responses.

As long as colleges function in our society as professional certification agencies, this type of student attitude is understandable and probably inevitable, but certain types of evaluation procedures exacerbate the problem. Exams and classroom management methods that depend upon uncertainty of content or timing not only generate student anxiety, but also tempt students to "psych out" their teacher. An evaluation instrument that lists a number of essay questions, topics, or skills to be selected by the instructor at the point of evaluation measures and promotes the tendency of students to try to overcome the natural asymmetry of the teacher/student relationship. Unscheduled quizzes and unsolicited requests to answer questions create a tense classroom atmosphere and perpetuate the adversarial teacher/student relationship inherited from high school. 
Where course content permits, exams should be open-book and the structure and timing of evaluation periods clearly forecast. If possible, students should be permitted to rework course requirements if dissatisfied with an initial grade.

\section{Conclusion}

Much of what Gilligan, Noddings, and others urge has been understood and put into practice for years by good teachers. Nonetheless, a perspicuous statement and justification of feminist pedagogy can point toward unsuspected insights and wider use of methods that have proven to be successful. Both deductive, lecture-oriented instructional methods and the more informal interpersonal approach advocated by Noddings and others have their place in value-laden courses, because real moral problems have both cognitive/intellectual and social/emotional aspects. An understanding of the multi-dimensional character of value conflicts can make more immediately apparent the relevance of moral rules and other general principles to appropriate behavior in morally complex situations. Conversely, showing students how moral principles can guide behavior by embedding them within classroom management can help bring to life what once seemed a series of arid abstractions.

\section{Bibliography}

Bennet, W.J., \& Delattre, E.J. (1978). Moral education in the schools. The Public Interest, Winter, 81-98.

Frankel, J.R. (1976). The Kohlberg bandwagon: Some reservations. Social Education, 40, 216-22.

Froming, W.J. (1978). The relationship of moral judgement, self-awareness, and sex to compliance behavior. Joumal of Humanistic Education and Development, 12(4), $396-409$.

Gilligan, C. (1982). In a different voice. Cambridge, Massachusetts: Harvard University Press.

Hayles, N.K. (1986). Anger in different voices: Carol Gilligan and The mill on the floss. Signs, 12(1), 23-39.

Kerber, L.K. (1986). On In a different voice: An interdisciplinary forum. Signs, 11(2), 304-33.

Kohlberg, L. (1981). Education for justice: A modern statement of the Socratic view. In The philosophy of moral development (pp. 29-48). New York: Harper \& Row.

Muuss, R.E. (1988). Carol Gilligan's theory of sex differences in the development of moral reasoning during adolescence. Adolescence, 23(89), 229-43.

Noddings, N. (1983). The promise of open education. Theory into Practice, 22(3), 182-89. 
Noddings, N. (1984). Caring: A feminine approach to ethics and moral education. Berkeley: University of California Press.

Noddings, N. (1987). Do we really want to produce good people? Joumal of Moral Education, 16(3), 177-88.

Noddings, N. (1988). An ethic of caring and its implications for instructional arrangements. American Joumal of Education, 96(2), 215-30.

Sandler, B. (1982). The classroom climate: $A$ chilly one for women? Washington, DC: Association of American Colleges.

Sichel, B.A. (1985). Woman's moral development in search of philosophical assumptions. Journal of Moral Education, 14(3), 149-61.

Stange, B.L. (1977). Levels of moral reasoning in education undergraduates. Saskatchewan Journal of Educational Research and Development, 8(1), 29-35.

Stonewater, B.J. (1987). Career traits, decision style, and Gilligan: Implications for counseling women. Journal of the National Association of Women Deans, Administrators and Counselors, 50(2), 17-26.

Walker, L.J. (1987). Moral stages and moral orientations in real-life and hypothetical dilemmas. Child Development, 58(3), 842-58.

West, J.D., \& Bursor, D.E. (1984). Gilligan and Kohlberg: Gender issues in moral development. Joumal of Humanistic Education and Development, 22(4), 134-42. 